leave of absence. They were isolated and they sought medical treatment according to their condition.

The personal protective equipment for the eye-care nursing staff, ophthalmology residents, and attending eye surgeons included Latex gloves, eye protection (goggles or face shields), a surgical-style face mask, a long-sleeved fluid-resistant gown, and disposable shoe covers. Prepacked sets including the aforementioned equipment were prepared for each individual and were delivered at the beginning of every shift. As advised by the European Society for Cataract and Refractive Surgery (ESCRS), protective shields were installed on slit-lamps.

The ophthalmologists used single-use cotton-swab applicators during examination to avoid touching the patient's face and eyelid. Hand washing was mandatory between each patient. Gloves were disposed after contact with the patient and hand washing with an alcohol-based antiseptic was performed subsequently.

In the midst of this crisis, hospitals continue to face shortages of personal protective equipment. We designated special safety measures including appropriate hand washing technique between each patient; other practices, such as the extended use of face masks, were also instructed. Transparency films were cut out to make face shields and plastic bags were used as shoe covers. The number of staff was also limited. These management strategies helped overcome the shortage and limit the spread of the virus.

The experience and preventive strategies mentioned should be of help in similar ophthalmic or subspecialty healthcare facilities. Ophthalmologists and local infection control teams should consider the regional viral extent when applying preventive measures. Hopefully, appropriate precautions will shorten the pandemic period and benefit the whole world.

Acknowledgments. None.

Financial support. No financial support was provided relevant to this article.

\section{References}

1. Coronavirus COVID-19 global cases by the Center for Systems Science and Engineering (CSSE). Johns Hopkins University website. https://coronavirus. jhu.edu/map.html. Updated March 26, 2020. Accessed March 26, 2020.

2. Important coronavirus updates for ophthalmologists. American Academy of Ophthalmology website. https://www.aao.org/headline/alert-importantcoronavirus-context. Updated March 25, 2020. Accessed March 29, 2020.

3. Lu C-w, Liu X-f, Jia Z-f. 2019-nCoV transmission through the ocular surface must not be ignored. Lancet 2020;395:e39.

4. Seah I, Agrawal R. Can the coronavirus disease 2019 (COVID-19) affect the eyes? A review of coronaviruses and ocular implications in humans and animals. Ocul Immunol Inflamm 2020;28:391-395.

5. Xia J, Tong J, Liu M, Shen Y, Guo D. Evaluation of coronavirus in tears and conjunctival secretions of patients with SARS-CoV-2 infection. J Med Virol 2020. doi: 10.1002/jmv.25725.

6. Sun X, Zhang X, Chen X, et al. The infection evidence of SARS-COV-2 in ocular surface: a single-center cross-sectional study. MedRxiv 2020 doi: 10.1101/2020.02.26.20027938.

7. Qing H, Li Z, Yang Z, et al. The possibility of COVID-19 transmission from eye to nose. Acta Ophthalmol (Copenh) 2020 [Epub ahead of print]. doi: 10.1111/aos.14412.

8. Lai THT, Tang EWH, Chau SKY, Fung KSC, Li KKW. Stepping up infection control measures in ophthalmology during the novel coronavirus outbreak: an experience from Hong Kong. Graefes Arch Clin Exp Ophthalmol 2020; 258:1049-1055.

9. Global surveillance for COVID-19 caused by human infection with COVID-19 virus: interim guidance. World Health Organization website. https://apps.who.int/iris/handle/10665/331506. Published March 20, 2020. Accessed April 21, 2020.

10. Interim infection prevention and control recommendations for patients with suspected or confirmed coronavirus disease 2019 (COVID-19) in healthcare settings. Center for Disease Control and Prevention website. https://www.cdc. gov/coronavirus/2019-ncov/infection-control/control-recommendations. html. Updated March 20, 2020. Accessed March 25, 2020.

\title{
Effective infection prevention and control strategies in a large, accredited, psychiatric facility in Singapore
}

\author{
Daniel Poremski MSc, $\mathrm{PhD}^{1}$ (1), Sandra H. Subner MSc${ }^{2}$, Grace F.K. Lam BHS ${ }^{1}$, Raveen Dev MSc ${ }^{1}$, \\ Yee Ming Mok MBBS, MMed ${ }^{1}$, Hong Choon Chua MBBS, MMed ${ }^{1}$ and Daniel SS Fung MBBS, MMed ${ }^{1}$ \\ ${ }^{1}$ Institute of Mental Health, Singapore, Singapore and ${ }^{2}$ National Healthcare Group, Singapore, Singapore
}

To the Editor-On January 14, 2020, Singapore, a population-dense equatorial island nation in Asia, experienced its first COVID-19 case. The spread of SARS-CoV-2 reached 100 people over the first 6 weeks of the infection. ${ }^{1}$ The country took measures to reduce the porosity of its borders and implemented special measures to limit community transmission without immediately closing schools and businesses. ${ }^{1,2}$ Because infections may spread quickly in

Author for correspondence: Daniel Poremski, E-mail: Daniel.poremski@mail.mcgill.ca Cite this article: Poremski D, et al. (2020). Effective infection prevention and control strategies in a large, accredited, psychiatric facility in Singapore. Infection Control \& Hospital Epidemiology, 41: 1238-1240, https://doi.org/10.1017/ice.2020.163 psychiatric facilities, ${ }^{3,4}$ special measures were introduced in such settings. Although the cultural setting and geographical location might be unique, Singapore's Institute of Mental Health (IMH) operations are similar to those of international medical facilities accredited by The Joint Commission. This structure lends to the generalizability of several of its operational strategies. Here we have summarized the steps taken at the IMH, Singapore's largest provider of tertiary mental health care, which has, as of April 28, 2020, prevented the spread of SARS-CoV-2 despite local community transmission. ${ }^{1}$

The IMH serves this nation's population of $\sim 6$ million; it employs $\sim 2,500$ staff and has a capacity of 2,000 inpatient beds. 
Table 1. Pandemic-Specific Infection Prevention and Control Strategies, Stratified by Level

\begin{tabular}{|c|c|c|}
\hline Hospital & Ward/Location & Individual \\
\hline $\begin{array}{l}\text { - Restricted access into IMH, only } \\
1 \text { entrance } \\
\text { - } 3 \text { visitor screening centers have } \\
\text { been set up } \\
\text { - Visitors must register and state the } \\
\text { purpose } \\
\text { of their visit and location of visit } \\
\text { - Temperature screening of all } \\
\text { visitors plus } \\
\text { travel history } \\
\text { - Restrictions on the number of } \\
\text { visitors: } \\
\text { only } 1 \text { visitor at a time per } \\
\text { inpatient; only } 1 \text { accompanying } \\
\text { person per outpatient } \\
\text { - Televisitation services for visitors } \\
\text { - Teleconsultation for medical } \\
\text { consultations } \\
\text { in nursing homes } \\
\text { - Home delivery of prescriptions }\end{array}$ & $\begin{array}{l}\text { - Isolation ward for potential infectious cases } \\
\text { (eg, respiratory symptoms) } \\
\text { - Enhanced pneumonia surveillance } \\
\text { - Modular system in the blocks; no cross-block } \\
\text { movement; split-mode operations } \\
\text { - No interward mixing } \\
\text { - Unidirectional flow in the outpatient clinic } \\
\text { - Reduction of outpatient appointments to lengthen the gap } \\
\text { between follow-up appointments where possible } \\
\text { - Negative pressure rooms ( } n=28 \text { ) } \\
\text { ECT service } \\
\text { - Segregation of inpatients and outpatients receiving service; } \\
\text { service provision is conducted by blocks; enhanced terminal } \\
\text { cleaning after each use } \\
\text { X-ray services } \\
\text { - Provision of services by block } \\
\text { Dental services } \\
\text { - Suspended service }\end{array}$ & $\begin{array}{l}\text { Patients } \\
\text { - Temperature surveillance of inpatients } \\
\text { twice daily } \\
\text { - Patients hands are sanitized every } 2 \mathrm{~h} \text { in } \\
\text { the wards } \\
\text { - Personal hygiene education for inpatients } \\
\text { - Patient vaccination program (flu and } \\
\text { pneumococcal) } \\
\text { - Suspension of group activities } \\
\text { Staff } \\
\text { - Staff wear surgical masks in the wards } \\
\text { - Personal portable hand sanitizer given to } \\
\text { all staff, changed every } 6 \text { mo } \\
\text { - Staff temperature screening twice daily } \\
\text { - Travel and leave restrictions } \\
\text { - Staff vaccination program (flu, MMR, hepatitis) } \\
\text { - All nonessential training has been suspended } \\
\text { - Essential training, ie, maintenance of } \\
\text { competency (eg, BCLS) continues } \\
\text { - Personal protective equipment training and } \\
\text { - Eudits } \\
\text { - Sisitors } \\
\text { - Aacilitate contact tracing } \\
\text { - All visitors to wardoring of staff temperature, travel, and } \\
\text { surveillance system } \\
\text { - }\end{array}$ \\
\hline
\end{tabular}

Note. IMH, Singapore Institute for Mental Health; ECT, electroconvulsive therapy; MMR, measles, mumps, rubella vaccine; BCLS, basic cardiac life support.

Occupancy reaches 51,000 patient bed days per month. The IMH receives $\sim 16,000$ emergency service visits ${ }^{5}$ and 36,000 outpatient visits, and it hosts 20,000 family visitors to inpatient wards each year. It is also a primary location for teaching. In 2005, the IMH was the first mental health institute to obtain Joint Commission International (JCI) accreditation in Asia.

The architecture of the 22-hectare campus emphasizes natural light and air circulation through every general ward yearround, made possible by the equatorial climate. The facility has 28 JCI-compliant high-efficiency particulate air (HEPA)filtered, negative-pressure, medical isolation units, and 14 of these have additional anterooms. Old and new administration buildings allow administrative departments to be physically split between buildings. Because standard infection prevention practices may not invariably prevent the spread of infections, ${ }^{4,6-8}$ additional measures were implemented to respond to the pandemic.

\section{Infection prevention and control strategies}

\section{Providing essential mental health services}

Providing mental health services is the mission of the IMH. However, certain aspects may need to be balanced to safeguard the sustained provision of services. First, care should always be provided with the least restrictive means. Finding this balance requires careful and constant assessment of risks and the effectiveness of current strategies. For example, completely suspending family visits may help reduce the risk of SARS-Cov-2 transmission considerably, but such a policy would be detrimental to the recovery of patients, and under the current risk assessment, it is a step too far.
The decision to reduce access to or suspend individual services entirely depends on (1) the risk of infection posed by the service, (2) the needs of patients, and (3) service alternatives. For example, outpatient services may introduce infection because physicians have inpatient and outpatient duties. Reducing the volume of outpatient services could help decrease risks. Patients with low levels of need are served via telehealth consultations. Medications are delivered by courier to reduce the volume of patients entering the facility.

\section{Preventing the introduction of infectious contagions}

A guiding principle of the infection prevention and control strategies is to recognize that patients and staff need to be equally considered to ensure that infections are avoided. Several general prevention strategies are used under normal risk of infection, ${ }^{9}$ and they are considered normal accreditation obligations. Special strategies introduced to keep infectious contagions out of the facilities are listed in Table 1.

\section{Resource management}

The sustainability of strategies is vital, especially when expecting a long pandemic. As such, policy makers must be mindful of the supply of consumables and labor. Managing consumables may depend on local supply chains. In Singapore, a national-level strategy ensures that personal protective equipment is available. Allocation is monitored down to the individual mask. This measure ensures that the demand for consumables can be quantified precisely.

Business continuity planning is a priority. To avoid quarantine of entire departments, each department has been split into individual units that conduct all the essential functions of the larger 
department. This isolates the departments similar to the encapsulated operation of the wards.

To ensure that staff are available, nonessential vacation allowances have been suspended. Because suspended travel may incur financial costs, one of the first items communicated to staff included the Ministry's intention to compensate staff for disruptions to personal travel. This action reduced anxiety and allowed personnel to focus on their duties.

Communication is vital. Regular updates are given to staff to inform them of essential developments, which are communicated via town halls, e-mails, and social media, depending on urgency. Senior management also increased the frequency of their presence in the wards to ensure staff engagement.

Recognition is important. Special compensation was announced for frontline staff. Although the actual reward for going above and beyond the call of duty may not come immediately, it is essential that staff be notified early that they will be recognized for their added effort.

In conclusion, infection prevention and control strategies come with varying degrees of immuration. Deploying a multipronged approach that addresses care and safety of staff and patients while underscoring the sustainability service provision is vital. It is imperative that healthcare organizations respond with overly cautious strategies and that they subsequently monitor the effect of these measures to balance the protection of patients with the tenet of providing the least restrictive service. In matters that are time sensitive, leaders should avoid fatiguing their staff with repeated policy changes because it will lead to complacency. The challenges of prolonged pandemics are felt by everyone, and ultimately, it is important to recognize and validate the contribution of individuals.

Acknowledgments. We would like to thank our international colleagues for sharing with us which of our strategies they found most useful.
Financial support. No financial support was provided relevant to this article.

Conflicts of interest. All authors report no conflicts of interest relevant to this article.

\section{References}

1. Ng Y, Li Z, Chua YX, et al. Evaluation of the effectiveness of surveillance and containment measures for the first 100 patients with COVID-19 in SingaporeJanuary 2-February 29, 2020. Morbid Mortal Wkly Rep 2020;69;307-311.

2. Wong JE, Leo YS, Tan CC. COVID-19 in Singapore-current experience: critical global issues that require attention and action. JAMA 2020 Feb 20 [Epub ahead of print]. doi: 10.1001/jama.2020.2467.

3. Weber DJ, Sickbert-Bennett EE, Vinjé J, et al. Lessons learned from a norovirus outbreak in a locked pediatric inpatient psychiatric unit. Infect Control Hosp Epidemiol 2005;26:841-843.

4. Fukuta Y, Muder RR. Infections in psychiatric facilities, with an emphasis on outbreaks. Infect Control Hosp Epidemiol 2013;34:80-88.

5. Poremski D, Kunjithapatham G, Koh D, Lim XY, Alexander M, Lee C. Lost keys: understanding service providers' impressions of frequent visitors to psychiatric emergency services in Singapore. Psychiatr Serv 2016;68:390-395.

6. Mada P, Saldana D, Castano G, Malus M, Sharon Adley N. Influenza outbreaks with a focus on closed psychiatric units: a review article. Glob J Infect Dis Clin Res 2018;4:1-3.

7. Bergin SM, Periaswamy B, Barkham T, et al. An outbreak of Streptococcus pyogenes in a mental health facility: advantage of well-timed whole-genome sequencing over EMM typing. Infect Control Hosp Epidemiol 2018;39: 852-860.

8. Sim K, Chong PN, Chan YH, Soon W. Severe acute respiratory syndromerelated psychiatric and posttraumatic morbidities and coping responses in medical staff within a primary healthcare setting in Singapore. J Clin Psychiatr 2004;65:1120-1127.

9. National Infection Prevention and Control Committee. The National Infection Prevention and Control Guidelines for Acute Healthcare Facilities. Singapore: Ministry of Health; 2017.

\title{
How we mitigated and contained the COVID-19 outbreak in a hemodialysis center: Lessons and experience
}

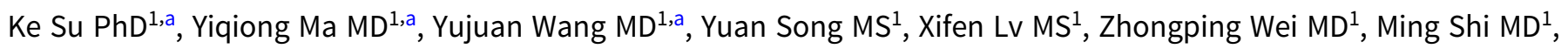 \\ Guohua Ding $M D^{1}$, Bo Shen $M D^{2}$ and Huiming Wang $M D^{1}$ \\ ${ }^{1}$ Department of Nephrology, Renmin Hospital of Wuhan University, Wuhan, Hubei, PR China and ${ }^{2}$ Department of Cardiology, Renmin Hospital of Wuhan \\ University, Wuhan, Hubei, PR China
}

To the Editor-COVID-19 has become a worldwide pandemic. After 2 months of strict control and prevention measures, the COVID-19 epidemic has been contained successfully in Wuhan. We have summarized lessons and experiences related to the reduction of nosocomial COVID-19 in the hemodialysis center for the benefit of healthcare providers and administrations outside China who are facing the challenges of the COVID-19 pandemic.

Author for correspondence: Huiming Wang, E-mail: rm000301@whu.edu.cn.

a Authors of equal contribution.

Cite this article: Su K, et al. (2020). How we mitigated and contained the COVID-19 outbreak in a hemodialysis center: Lessons and experience. Infection Control \& Hospital Epidemiology, 41: 1240-1242, https://doi.org/10.1017/ice.2020.161
Hemodialysis patients are particularly vulnerable to infection and may exhibit greater variations in clinical symptoms and infectivity. Hemodialysis patients are susceptible to infection for the following reasons: (1) Hemodialysis patients require frequent transportation to and from the hospital and their residence to receive dialysis 2 to 3 times per week, which increases the risk of COVID-19 transmission. (2) Hemodialysis patients often require care from family members or caregivers, and if a caregiver is infected, they can transmit the virus to all close contacts, including the hemodialysis patient. (3) The hemodialysis center is a relatively open space with personnel (eg, medical staff and facility workers), patients, and their family members. Thus, many people gather in hemodialysis centers, posing a risk for a virus transmission cluster.

(c) 2020 by The Society for Healthcare Epidemiology of America. All rights reserved. This is an Open Access article, distributed under the terms of the Creative Commons Attribution licence (http://creativecommons.org/licenses/by/4.0/), which permits unrestricted re-use, distribution, and reproduction in any medium, provided the original work is properly cited. 